\title{
Denosumab Related Osteonecrosis of Jaw: a Case Report
}

\author{
Marco Vinícius de Sales Lima ${ }^{1}$, Jaqueline Rizzato ${ }^{1}$, Daniella Varzea Gracindo Marques ${ }^{1}$, Dárcio \\ Kitakawa $^{2}$, Felipe da Silva Peralta ${ }^{1}$, Alexandre Prado Scherma ${ }^{1}$, Luis Felipe C. S. Carvalho ${ }^{1,2}$
}

${ }^{1}$ Faculdade De Odontologia, Da Universidade De Taubaté (Unitau), Taubaté - SP, Brazil.

${ }^{2}$ Centro Universitário Braz Cubas, Mogi das Cruzes-SP, Brasil.

\author{
Corresponding Author: \\ Luis Felipe das Chagas e Silva de Carvalho \\ Taubaté-SP \\ Brazil \\ Phone: +5512981016687 \\ E-mail: luisfelipecarvalho@hotmail.com
}

\begin{abstract}
Background: This case report shows an affected postmenopausal patient with medicaments related osteonecrosis of the jaw injury associated with increased use of bisphosphonates and Prolia ${ }^{\circledR}$ (denosumab) for the treatment of osteoporosis. The mechanism of action of the receptor activates the denosumab of the nuclear-kB factor binding and makes nuclear-kB Factor, reducing bone volume and reabsorption in the trabecular and cortical bones and, consequently, decreasing an incidence of fractures and maintaining a bone formation. The bone physiology regulated by the hormones calcitonin, parathormone and vitamin D also undergoes interference.

Methods: The injury was located around a dental implant in region \#24 and \#25 and the patient complained of pain, bleeding, oedema, and halitosis for more than two months, that the dental implant had been installed five years before. According to the clinical findings, the patient presented the exposed and necrotic bone in the region of \#24 and \#25 and with the radiographs found, it was observed as extensive bone destruction adjacent to the dental implant.

Results: Patient was referred to the maxillofacial surgeon that performed the removal of bone sequestration and dental implant in the region affected. After that, the patient has been accompanied for a year.

Conclusions: Patients taking medications for osteoporosis or cancer need to receive special attention from the dentist. Invasive procedures on the jaw bone of patients taking these medications may cause osteonecrosis of the jaw. When diagnosed, osteonecrosis of the jaw should be treated surgically in conjunction with antibiotic therapy and patients should be monitored.
\end{abstract}

Keywords: bisphosphonates; denosumab; drugs; osteonecrosis.

\author{
Accepted for publication: 29 December 2018 \\ To cite this article: \\ de Sales Lima MV, Rizzato J, Gracindo Marques DV, Kitakawa D, da Silva Peralta F, Prado Scherma A, Carvalho LFCS. \\ Denosumab Related Osteonecrosis of Jaw: a Case Report \\ J Oral Maxillofac Res 2018;9(4):e5 \\ URL: http://www.ejomr.org/JOMR/archives/2018/4/e5/v9n4e5.pdf \\ doi: $10.5037 /$ jomr.2018.9405
}




\section{INTRODUCTION}

The osteonecrosis of the jaw (ONJ), also called as avascular necrosis, aseptic necrosis or ischemic necrosis of bone, is the death of a bone segment caused by an insufficient blood supply. Typical symptoms includes pain, limited movements of the affected articulation. ONJ affects the quality of life and makes the oral hygiene and feeding difficult [1]. Affects the quality of life and makes the oral hygiene and feeding difficult [1]. Medication related ONJ (MRONJ) can be induced by bisphosphonates (BPs) and others anticancer treatment such as radiotherapy, and can be potentiate by chemotherapy agents that inhibit tyrosine kinase such as sunitinib or imatinib [2]. The denosumab medication, both Prolia ${ }^{\circledR}$ (Amgen Biotecnologia do Brasil Ltda.) and Xgeva ${ }^{\circledR}$ (Amgen Inc., California, USA), is also associated with ONJ [3].

Osteoporosis patients using antiresorptive drugs (BPs) may have some adverse reactions such as esophagitis, musculoskeletal pain, hypocalcaemia, ocular inflammation and bisphosphonates related to ONJ (BRONJ), despite this medicine is well tolerated. More recently, MRONJ has been observed in association with other medications such as denosumab and antiangiogenic drugs [4]. In case of low compliance with BPs due to gastrointestinal trouble and impaired renal function, a biannual subcutaneous administration of $60 \mathrm{mg}$ of denosumab can be a better choice for osteoporosis treatment [ $\underline{5}$. There are few cases of MRONJ associated with sunitinib or imatinib used simultaneously with BPs, and a rare case reported in the literature of ONJ induced by monotherapy imatinib [2].

Antiresorptive include five principal classes of agents: bisphosphonates, oestrogens, selective oestrogen receptor modulators, calcitonin and monoclonal antibodies such as denosumab. BPs are the most widely used first-line antiresorptive therapy and are recommended for patients with osteoporosis and individuals with a high risk of fracture []. Denosumab has shown efficacy against vertebral, nonvertebral and hip fractures [7].

Cases of ONJ associated with denosumab have been described since 2010. Qaisi et al. [ $\underline{8}$ ] has reported a rare case of a 65 year-old female patient, who developed a life threatening ONJ with sepsis shortly after switching from BPs to denosumab (Prolia ${ }^{\circledR}$ ) for the treatment of osteoporosis. The patient was deemed not a good surgical candidate at the time. After a while, she had near complete recovery with no surgical intervention. You et al. [9] described a case of a 56 year-old woman with approximately $1 \mathrm{~cm}$ of exposed bone that had no clinical evidence of sequestration, with the patient being treated with surgical removal of the necrotic bone after 6 months of denosumab or placebo discontinuation. Also, men with bone metastases of prostate cancer who are taking denosumab has some risk of developing ONJ, as in a case of a 86 year-old patient reported by Yoshimura et al. [10].

Oncologic patients may have ONJ and metastasis in the same site of the jaw. Corsi et al. [11] has reported a case of oncologic 54-year-old woman with ONJ associated with BP in December of 2007. The patient was treated for a breast carcinoma in 2002 and later was treated with a monthly intravenous infusion of $4 \mathrm{mg}$ zoledronic acid for one year for treating vertebral bone metastasis. She had metastasis of the breast carcinoma in the same site of the sequestration bone. Dental implants also are a risk factor for breast cancer patients using BPs [12]. A case of 74 and 72 women was reported by Han et al. [13], both diagnosed with BRONJ with bone exposure on the left maxillary edentulous area. The two patients were treated and have had the cessation of BPs therapy.

The purpose of this study is to present a case of the osteonecrosis of the jaw induced by bisphosphonates and denosumab therapy.

\section{CASE DESCRIPTION AND RESULTS}

Patient, female, 83 years old, was referred by an implantodontist of the Healthcare facility in January of 2017 to evaluate the supposedly necrotic area laterally \#25 (implant) and \#24 (tooth). Complaining of pain and swelling that had persisted for 2 months, also felted bleeding and bad smell. The surgeondentist administered antibiotic, anti-inflammatory, analgesic medicamental treatment and significant improvement was reported. Clinically, could be observed exposed necrotic bone area and bad smell at the place that should be of the \#24 and distal \#25 teeth related to an osseointegrated implant, which was installed about 5 years ago (Figure 1). Indeed the patient also referred the extraction of the \#24 tooth around two weeks before the exposition of necrotic bone in January of 2017 due to extern apical root reabsorption disease. Before the extraction, there were no symptoms of osteonecrosis, only the severe commitment of the periodontal structure disease caused by the extern apical root reabsorption was present, which led to the extraction. Radiographically, 


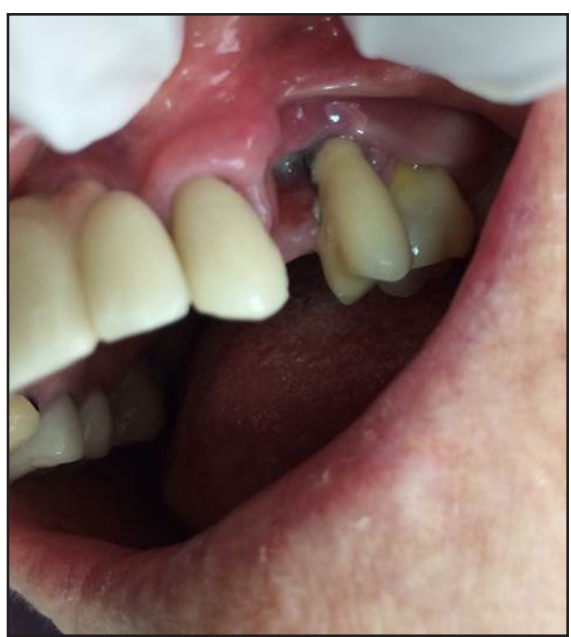

Figure 1. Clinical aspect (\#24 and \#25) presenting osteonecrosis of the jaw.

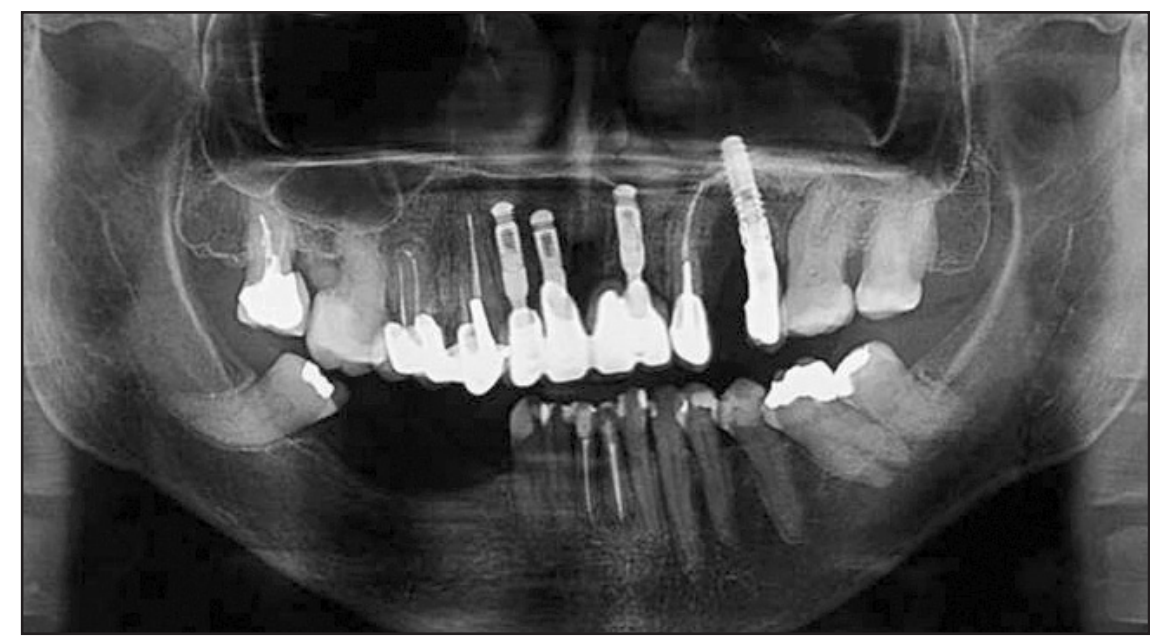

Figure 2. Preoperative panoramic radiograph showing the osteonecrosis of the jaw as a radiolucid area adjacent to the dental implant \#25. extensive bone destruction was observed adjacent to the implant (tooth \#25) in panoramic and periapical $\mathrm{X}$-rays (Figure 2 and 3). The panoramic radiograph of tooth \#24 before the extraction (Figure 4) did not show symptoms of the osteonecrosis, the invasive procedure of the extraction was certainly the main factor that caused the ONJ. After the anamnesis, the patient related taking the Prolia ${ }^{\circledR} 60 \mathrm{mg} / \mathrm{ml}$, injected twice a year, 3 years ago. Prior to Prolia ${ }^{\circledR}$, the patient had used alendronate sodium alendronate $70 \mathrm{mg}\left(\right.$ Fosamax $^{\circledR}$ Plus D - Merck Sharp \& Dohme Farmacêutica LTDA), weekly, for 15 years; levotiroxina (Euthyrox ${ }^{\circledR}$; Merck S.A., Rio de Janeiro, Brasil) and was supplemented by calcium and vitamin $\mathrm{D}$ by orientation and prescription by responsible doctor. Overall, the patient's general health was good. With a clinical diagnosis of ONJ related to denosumab, the patient was referred to a maxillofacial surgeon, who performed the surgical procedure of removal of the bone sequestration and removal of the associated implant. The patient is being followedup and after 8 months of the surgical procedure no recurrence was observed (Figure 5 and 6).

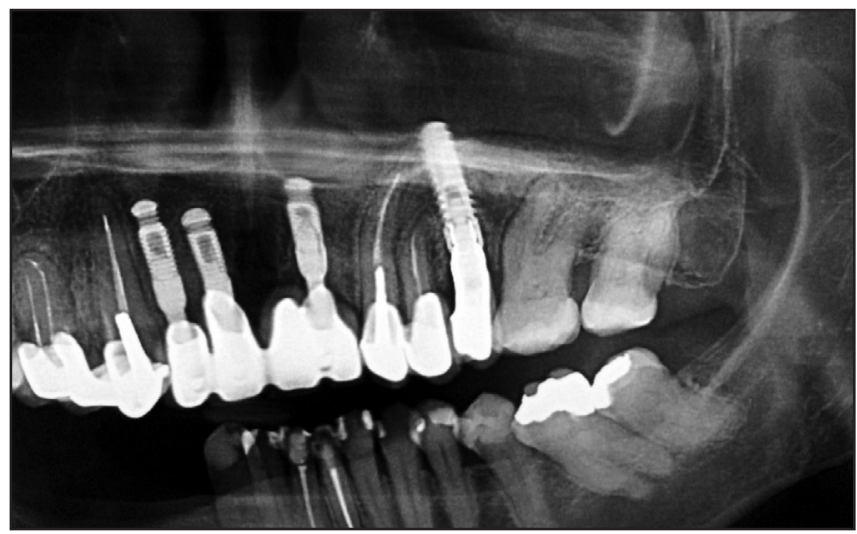

Figure 4. Panoramic image before the extraction of the \#24 tooth.

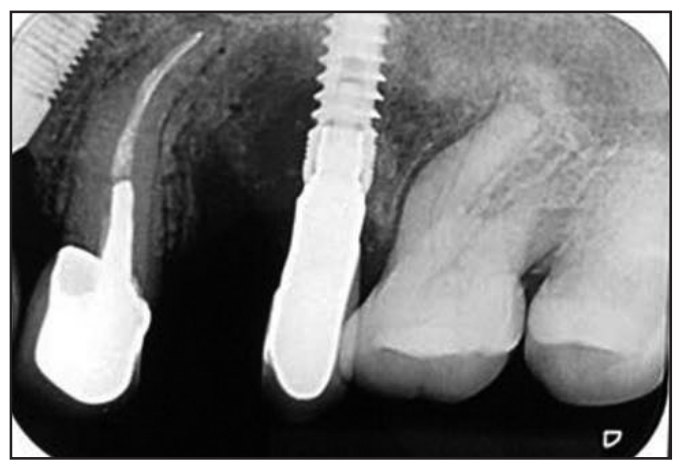

Figure 3. Periapical radiograph of pre molar showing the radiolucid area adjacent to the dental implant $\# 25$.

\section{DISCUSSION}

ONJ can be induced by BPs and other anticancer treatment. ONJ is potentiating by antiangiogenic drugs such as sunitinib, a medication approved for renal cell carcinoma [14]. A recently retrospective study [3] at the Cancer Institute of Lorraine (ICL),

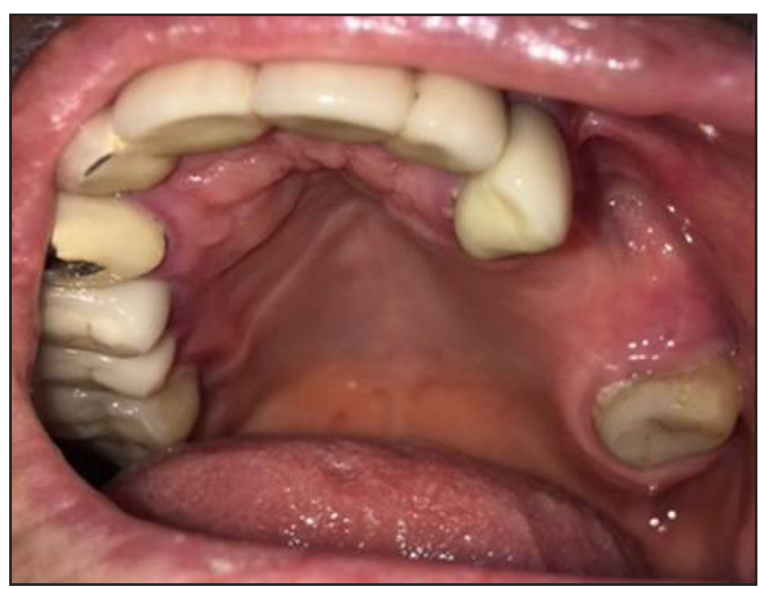

Figure 5. Clinical aspect after 8 months of the surgical procedure. No recurrence of the osteonecrosis of the jaw was observed. 


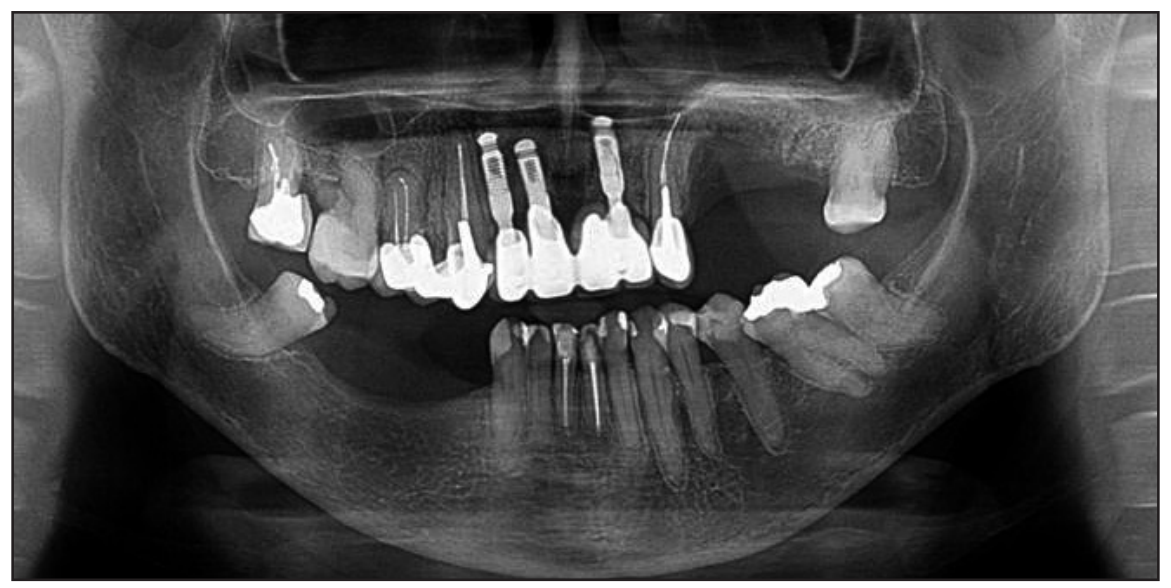

Figure 6. Panoramic radiograph of 8 months follow-up.

that inserted 141 patients using denosumab $\mathrm{Xgeva}^{\circledR}$, which 9 of them developed ONJ, concluded that this medication associated with invasive dental procedure can develop ONJ []ㅡ. The pharmacology of denosumab may resolve the ONJ more rapidly than the BPs. In our case, the denosumab medication used by the patient was the Prolia ${ }^{\circledR}$, which was referred to her ONJ, that is indicated for the treatment of postmenopausal women with osteoporosis with high risk for fracture [15].

Previously, the patient was treated with the BP alendronate therapy for 15 years, changing then for Prolia ${ }^{\circledR}$ injected. Kendler et al. [16] showed that the transition from weekly alendronate for several years to the treatment with Prolia ${ }^{\circledR}$ injected twice yearly increases the bone mineral density and reduces bone turnover. Despite this, the study concludes that women with low bone density have done this transition safely. However, more of the studies have to be done. Tooth extractions, mandibular exostoses, periodontal disease, local trauma and dental implants have been suggested to be common precipitating factors for ONJ and the mandible is the most common site for this lesion [17].

Denosumab function mechanism inhibits the receptor activator of nuclear factor- $\mathrm{\kappa B}$ binding (RANKL) and the receptor activator of nuclear factor- $\kappa B$ (RANK) complex. The RANKL-RANK complex is essential in osteoclast-mediated bone resorption. Osteoporosis and bone metastasis could lead a huge bone resorption, the denosumab interrupt this pathophysiologic process. Inhibition of this complex reduces bone turnover and resorption, thereby increasing bone mass and strengthening cortical and trabecular bone, presenting the risk of ONJ [ $\underline{3}]$.

Patients with ONJ have severe pain and difficult on performing common activities on day by day like eating, speaking and brushing teeth. The population at risk for ONJ is large and expanding, and the public health implications may be substantial. A study that analysed the quality of life (QoL) of 34 patients with cancer and BRONJ suggested that ONJ significantly affects the QoL of patients with cancer, being the intravenous and oral bisphosphonate an important decision of choice of treatment for the patient and the dentist to take [18]. Corraini et al. [19] analysed from the eligibility period that started on $15^{\text {th }}$ of October 2010 to $31^{\text {st }}$ of December 2015 the association between cancer patients with ONJ without a diagnosis of osteoporosis and survival among patients in the median age of 68 years with cancer, being treated with BPs. During average followup of 1 to 4 years in the ONJ cohort, less than half of the patients with ONJ survived for 3 years, being ONJ associated with significantly reduce of survival among patients with cancer treated with bone-targeted agents.

Stockmann et al. [1] evaluated that the different imaging techniques shows the extent of the bone affected most precisely. The clinical examination do not allow to determine the extent of the ONJ, which is so important for the surgical treatment taking into consideration that the surgeon have to remove the bone sequestration with a security limitation. Panoramic radiographs, computed tomography (CT) and magnetic resonance imaging (MRI) scans were obtained. The panoramic radiograph is the technique most used by dentists for patients with ONJ, but have poor detectability for the determination of the extent and delimitation of ONJ for showing the image only in two-dimensions, otherwise the MRI and CT can have high detectability for the lesion and CT scans can provide detailed information and allow estimating real extent of ONJ. In present study panoramic radiogrpah was obtained for diagnostics and safe area was taken in consideration in the surgery procedure to avoid recurrence of the lesion [1]. 
The ONJ does not always present with oral mucosa fenestration and necrotic bone exposure, so the dentist should be informed if the patient is using medication for osteoporosis, cancer or other treatment that decreases the bone turnover and give a differential diagnosis, based on excluding common jawbone diseases known to cause similar manifestations. Clinical manifestations of ONJ include otherwise unexplained jawbone pain, fistula/ sinus tract, tooth loss, swelling and, in advanced cases, pathological fracture of the mandible, reducing the QoL [20].

Troeltzsch et al. [21] analysed 34 patients receiving antiresorptive drugs in high doses with a total of 117 dental implants of various types, lengths and manufacturers. There is very little information about the implications of high-dose antiresorptive agents administration on implant dentistry. Patients with MRONJ and implants are relatively high as $56 \%$ of all MRONJ cases evolved in the vicinity of dental implants. Troeltzsch et al. [21] has considered the hypothesis that peri-implantitis may be a risk factor for peri-implant MRONJ, more studies involving peri-implant MRONJ need to be done. The dental implant is not a cause for the ONJ, but the invasive procedure in patients receiving these drugs probably causes the disease. The long history of antiresorptive drugs should be taken in consideration. It remains unclear, whether the surgical procedure of implant placement itself constitutes a trigger factor of peri-implant MRONJ [21]. Thus, according to the current guidelines, dental implant placement is not contraindicated in osteoporotic patients, but they have to receive special attention, and be followed-up with images monitoring [22]. In the presented patient, the ONJ was at the premolar region, around the dental implant, and not associated with the implant itself, but with medications taken by the patient.

In order to test the effects of denosumab or placebo, postmenopausal women with osteoporosis, between the age of 60 and 90 , received $60 \mathrm{mg}$ subcutaneously twice yearly, for 36 months, for prevention of osteoporosis related fractures. There was no increase in the risk of cancer, infection, cardiovascular disease, delayed fracture healing or hypocalcemia, and no cases of ONJ or adverse reactions to the injection of denosumab in this study. Reduction in the risk of vertebral, non-vertebral and hip fractures in women with osteoporosis was noticed [23]. In this study, the medicine denosumab was associated with patient's ONJ. Our patient had taken BP for a long period of time. In contrast to our study, Cummings et al. [23] excluded the patients medicated with BPs in the past 5 years.
In the osteoporosis patient population, the incidence of ONJ was estimated at $0.001 \%$ to $0.01 \%$, marginally higher than the incidence in the general population $(<0.001 \%)$. Other risk factors for ONJ include glucocorticoid use, maxillary or mandibular bone surgery, poor oral hygiene, chronic inflammation, diabetes mellitus, ill-fitting dentures, as well as other drugs, including antiangiogenic agents. The treatment for ONJ can be invasive or conservative, due to a series of factors - stage of the disease, size of the lesions and presence of contributing drug therapy and comorbidity. Conservative therapy includes topical antibiotic, oral rinses and systemic antibiotic therapy. Localized surgical debridement is indicated in advanced non-responsive disease and has been successful [24].

A recent study by Eiken et al. [25] surgically treated ONJ in over 60,000 patients' alendronate users in Denmark. One hundred seven patients patients received surgery for ONJ. The study suggests that alendronate treatment increases the risk of surgical intervention, and patients receiving this medication should receive an extra attention [25]. It is better to prevent MRONJ in patients who are about to begin the BP intravenous treatment, receiving a complete oral and dental examination, having a panoramic radiograph and preventing an invasive oral procedure [26].

Reducing BP dose also prevents ONJ in the context of oncology practice; giving three-monthly administration of intravenous BP is safer than monthly administration. As Reid [17] showed in his study, aggressive surgical intervention may be counterproductive, if it is necessary an invasive treatment, controlling the biofilm may help in the result. More studies have to be done to take a conclusion, but in case of the necessity of a invasive procedure, the dentist should solicit the reduction for the dose of BP. Many dentists have failed to appreciate the difference in BP doses between oncology and osteoporosis patients and the attendant difference in ONJ prevalence [17].

Our patient was referred to a maxillofacial surgeon for a surgical treatment for remove the bone sequestration on the jaw and removal of the dental implant associated to the ONJ. After the surgical treatment, the patient stopped the treatment with the Prolia ${ }^{\circledR}$ medicine and has being followed-up for one year since that.

Regard BPs, and according to the literature [24], the discontinuation of it for days or months after years of use did not decrease the risk of osteonecrosis since the BPs accumulates and takes years to disintegrate from the bone structure [ $\underline{8}]$. Concerning the denosumab, 
it is more difficult to state, since the drug has use that is more recent, more experienced researchers and clinicians suggest that discontinuation may accelerate the healing process of osteonecrosis [9]. We conclude that the most important to prevent the development of osteonecrosis is correct prevention with the use of systemic and topical antibiotics and periodic followup visits.

\section{CONCLUSIONS}

Osteonecrosis of the jaw is associated with antiresorptive and antiangiogenic medication, this correlation has been unanimously accepted and because of that patients that use these medications should receive more attention to the issue of oral care. In the present case report the patient was under bisphosphonates and denosumab therapy for osteoporosis treatment and an osteonecrosis of the jaw was diagnosed. A surgical removal of the affected tissues, including the affected dental implant was performed. The patient has being followed-up for 8 months since the surgical treatment without any signal of complications.

\section{ACKNOWLEDGMENTS AND DISCLOSURE STATEMENTS}

The authors report no conflicts of interest related to this study.

Luis Felipe das Chagas e Silva de Carvalho would like to thank Coordenação de Aperfeiçoamento de Pessoal de Nível Superior (CAPES) PNPD Odontologia - Universidade de Taubaté, and Centro Universitário Braz Cubas for the Scientific Initiation Program.

\section{REFERENCES}

1. Stockmann P, Hinkmann FM, Lell MM, Fenner M, Vairaktaris E, Neukam FW, Nkenke E. Panoramic radiograph, computed tomography or magnetic resonance imaging. Which imaging technique should be preferred in bisphosphonateassociated osteonecrosis of the jaw? A prospective clinical study. Clin Oral Investig. 2010 Jun;14(3):311-7. [Medline: 19513765] [doi: 10.1007/s00784-009-0293-1]

2. Viviano M, Rossi M, Cocca S. A rare case of osteonecrosis of the jaw related to imatinib. J Korean Assoc Oral Maxillofac Surg. 2017 Apr;43(2):120-124. [Medline: 28462197] [PMC free article: 5410424] [doi: 10.5125/jkaoms.2017.43.2.120]

3. Egloff-Juras C, Gallois A, Salleron J, Massard V, Dolivet G, Guillet J, Phulpin B. Denosumabrelated osteonecrosis of the jaw: A retrospective study. J Oral Pathol Med. 2018 Jan;47(1):66-70. [Medline: 28977694] [doi: 10.1111/jop.12646]

4. Aljohani S, Fliefel R, Ihbe J, Kühnisch J, Ehrenfeld M, Otto S. What is the effect of anti-resorptive drugs (ARDs) on the development of medication-related osteonecrosis of the jaw (MRONJ) in osteoporosis patients: A systematic review. J Craniomaxillofac Surg. 2017 Sep;45(9):1493-1502. [Medline: 28687467] [doi: 10.1016/j.jcms.2017.05.028]

5. Kim SY, Ok HG, Birkenmaier C, Kim KH. Can denosumab be a substitute, competitor, or complement to bisphosphonates? Korean J Pain. 2017 Apr;30(2):86-92. [Medline: 28416991] [PMC free article: 5392661] [doi: 10.3344/kjp.2017.30.2.86]

6. Chen JS, Sambrook PN. Antiresorptive therapies for osteoporosis: a clinical overview. Nat Rev Endocrinol. 2011 Sep 6;8(2):81-91. [Medline: 21894214] [doi: 10.1038/nrendo.2011.146]

7. Reginster JY, Neuprez A, Beaudart C, Lecart MP, Sarlet N, Bernard D, Disteche S, Bruyere O. Antiresorptive drugs beyond bisphosphonates and selective oestrogen receptor modulators for the management of postmenopausal osteoporosis. Drugs Aging. 2014 Jun;31(6):413-24. [Medline: 24797286] [PMC free article: 4033814] [doi: 10.1007/s40266-014-0179-z]

8. Qaisi M, Hargett J, Loeb M, Brown J, Caloss R. Denosumab Related Osteonecrosis of the Jaw with Spontaneous Necrosis of the Soft Palate: Report of a Life Threatening Case. Case Rep Dent. 2016;2016:5070187. [Medline: 27648313] [PMC free article: $\underline{5018314}$ ] [doi: 10.1155/2016/5070187]

9. You Tm, Lee KH, Lee SH, Park W. Denosumab-related osteonecrosis of the jaw: a case report and management based on pharmacokinetics. Oral Surg Oral Med Oral Pathol Oral Radiol. 2015 Nov;120(5):548-53. [Medline: 26337218] [doi: 10.1016/j.0000.2015.07.017]

10. Yoshimura H, Ohba S, Yoshida H, Saito K, Inui K, Yasui R, Ichikawa D, Aiki M, Kobayashi J, Matsuda S, Imamura Y, Sano K. Denosumab-related osteonecrosis of the jaw in a patient with bone metastases of prostate cancer: A case report and literature review. Oncol Lett. 2017 Jul;14(1):127-136. [Medline: 28693144] [PMC free article: 5494808] [doi: $10.3892 / 01.2017 .6121]$

11. Corsi A, Ungari C, Riminucci M, Agrillo A. Bisphosphonate-Related Osteonecrosis and Metastasis Within the Same Site of the Jaw. J Oral Maxillofac Surg. 2017 Aug;75(8):1679-1684. [Medline: 28188075] [doi: 10.1016/j.joms.2017.01.008]

12. Matsuo A, Hamada H, Takahashi H, Okamoto A, Kaise H, Chikazu D. Evaluation of dental implants as a risk factor for the development of bisphosphonate-related osteonecrosis of the jaw in breast cancer patients. Odontology. 2016 Sep;104(3):363-71. [Medline: 25956267] [doi: 10.1007/s10266-015-0207-4] 
13. Han JW. Bisphosphonate related osteonecrosis of the jaws: report of two cases. Imaging Sci Dent. 2011 Sep;41(3): 129-34. [Medline: 22010070] [PMC free article: 3189537] [doi: 10.5624/isd.2011.41.3.129]

14. Ashrafi F, Derakhshandeh A, Movahedian B, Moghaddas A. Osteonecrosis of the Jaws in Patient Received Bisphosphonates and Sunitinib Separately: A Case Report. J Res Pharm Pract. 2017 Jul-Sep;6(3):182-185. [Medline: 29026845] [PMC free article: 5632940] [doi: 10.4103/jrpp.JRPP $17 \quad 36$ ]

15. Green W. Denosumab (Prolia) Injection: A New Approach to the Treatment of Women With Postmenopausal Osteoporosis. Pharmacy and Therapeutics. 2010 Oct;35(10):553-9. [PMC free article: 2957751]

16. Kendler DL, Roux C, Benhamou CL, Brown JP, Lillestol M, Siddhanti S, Man HS, San Martin J, Bone HG. Effects of denosumab on bone mineral density and bone turnover in postmenopausal women transitioning from alendronate therapy. J Bone Miner Res. 2010 Jan;25(1):72-81. [Medline: 19594293] [doi: 10.1359/jbmr.090716]

17. Reid IR. Osteonecrosis of the jaw: who gets it, and why? Bone. 2009 Jan;44(1):4-10. [Medline: 18948230] [doi: 10.1016/j.bone.2008.09.012]

18. Miksad RA, Lai KC, Dodson TB, Woo SB, Treister NS, Akinyemi O, Bihrle M, Maytal G, August M, Gazelle GS, Swan JS. Quality of life implications of bisphosphonate-associated osteonecrosis of the jaw. Oncologist. 2011;16(1):121-32. [Medline: 21212433] [PMC free article: $\underline{3228058}$ ] [doi: 10.1634/theoncologist.2010-0183]

19. Corraini P, Heide-Jørgensen U, Schiødt M, Nørholt SE, Acquavella J, Sørensen HT, Ehrenstein V. Osteonecrosis of the jaw and survival of patients with cancer: a nationwide cohort study in Denmark. Cancer Med. 2017 Oct;6(10):2271-2277. [Medline: 28941210] [PMC free article: 5633555] [doi: 10.1002/cam4.1173]

20. Campisi G, Fedele S, Fusco V, Pizzo G, Di Fede O, Bedogni A. Epidemiology, clinical manifestations, risk reduction and treatment strategies of jaw osteonecrosis in cancer patients exposed to antiresorptive agents. Future Oncol. 2014 Feb;10(2):257-75. [Medline: 24490612] [doi: 10.2217/fon.13.211]

21. Troeltzsch M, Cagna D, Stähler P, Probst F, Kaeppler G, Troeltzsch M, Ehrenfeld M, Otto S. Clinical features of periimplant medication-related osteonecrosis of the jaw: Is there an association to peri-implantitis? J Craniomaxillofac Surg. 2016 Dec;44(12):1945-1951. [Medline: 27836551] [doi: 10.1016/j.jcms.2016.09.018]

22. Bedogni A, Bettini G, Totola A, Saia G, Nocini PF. Oral bisphosphonate-associated osteonecrosis of the jaw after implant surgery: a case report and literature review. J Oral Maxillofac Surg. 2010 Jul;68(7):1662-6. [Medline: 20561470] [doi: 10.1016/j.joms.2010.02.037]

23. Cummings SR, San Martin J, McClung MR, Siris ES, Eastell R, Reid IR, Delmas P, Zoog HB, Austin M, Wang A, Kutilek S, Adami S, Zanchetta J, Libanati C, Siddhanti S, Christiansen C; FREEDOM Trial. Denosumab for prevention of fractures in postmenopausal women with osteoporosis. N Engl J Med. 2009 Aug 20;361(8):756-65. [Medline: 19671655] [doi: 10.1056/NEJMoa0809493]

24. Khan AA, Morrison A, Hanley DA, Felsenberg D, McCauley LK, O’Ryan F, Reid IR, Ruggiero SL, Taguchi A, Tetradis S, Watts NB, Brandi ML, Peters E, Guise T, Eastell R, Cheung AM, Morin SN, Masri B, Cooper C, Morgan SL, ObermayerPietsch B, Langdahl BL, Al Dabagh R, Davison KS, Kendler DL, Sándor GK, Josse RG, Bhandari M, El Rabbany M, Pierroz DD, Sulimani R, Saunders DP, Brown JP, Compston J; International Task Force on Osteonecrosis of the Jaw. Diagnosis and management of osteonecrosis of the jaw: a systematic review and international consensus. J Bone Miner Res. 2015 Jan;30(1):3-23. [Medline: 25414052] [doi: 10.1002/jbmr.2405]

25. Eiken PA, Prieto-Alhambra D, Eastell R, Abrahamsen B. Surgically treated osteonecrosis and osteomyelitis of the jaw and oral cavity in patients highly adherent to alendronate treatment: a nationwide user-only cohort study including over 60,000 alendronate users. Osteoporos Int. 2017 Oct;28(10):2921-2928. [Medline: 28664276] [doi: $10.1007 / \mathrm{s} 00198-017-4132-\mathrm{y}$ ]

26. Bonacina R, Mariani U, Villa F, Villa A. Preventive strategies and clinical implications for bisphosphonate-related osteonecrosis of the jaw: a review of 282 patients. J Can Dent Assoc. 2011;77:b147. [Medline: 22129778]

\section{To cite this article:}

de Sales Lima MV, Rizzato J, Gracindo Marques DV, Kitakawa D, da Silva Peralta F, Prado Scherma A, Carvalho LFCS. Denosumab Related Osteonecrosis of Jaw: a Case Report

J Oral Maxillofac Res 2018;9(4):e5

URL: http://www.ejomr.org/JOMR/archives/2018/4/e5/v9n4e5.pdf

doi: $\underline{10.5037 / \text { jomr.2018.9405 }}$

Copyright (C) de Sales Lima MV, Rizzato J, Gracindo Marques DV, Kitakawa D, Peralta F, Scherma A, Carvalho LFCS. Published in the JOURNAL OF ORAL \& MAXILLOFACIAL RESEARCH (http://www.ejomr.org), 30 December 2018. This is an open-access article, first published in the JOURNAL OF ORAL \& MAXILLOFACIAL RESEARCH, distributed under the terms of the Creative Commons Attribution-Noncommercial-No Derivative Works 3.0 Unported License, which permits unrestricted non-commercial use, distribution, and reproduction in any medium, provided the original work and is properly cited. The copyright, license information and link to the original publication on (http://www.ejomr.org) must be included. 